\title{
APPARENT DENSITY OF SCHISTOSOMA MANSONI AND FASCIOLA HEPATICA EGGS 1.2
}

Isopynic centrifugation, in which the material of interest is centrifuged in a density gradient until it comes to equilibrium at a density equal to that
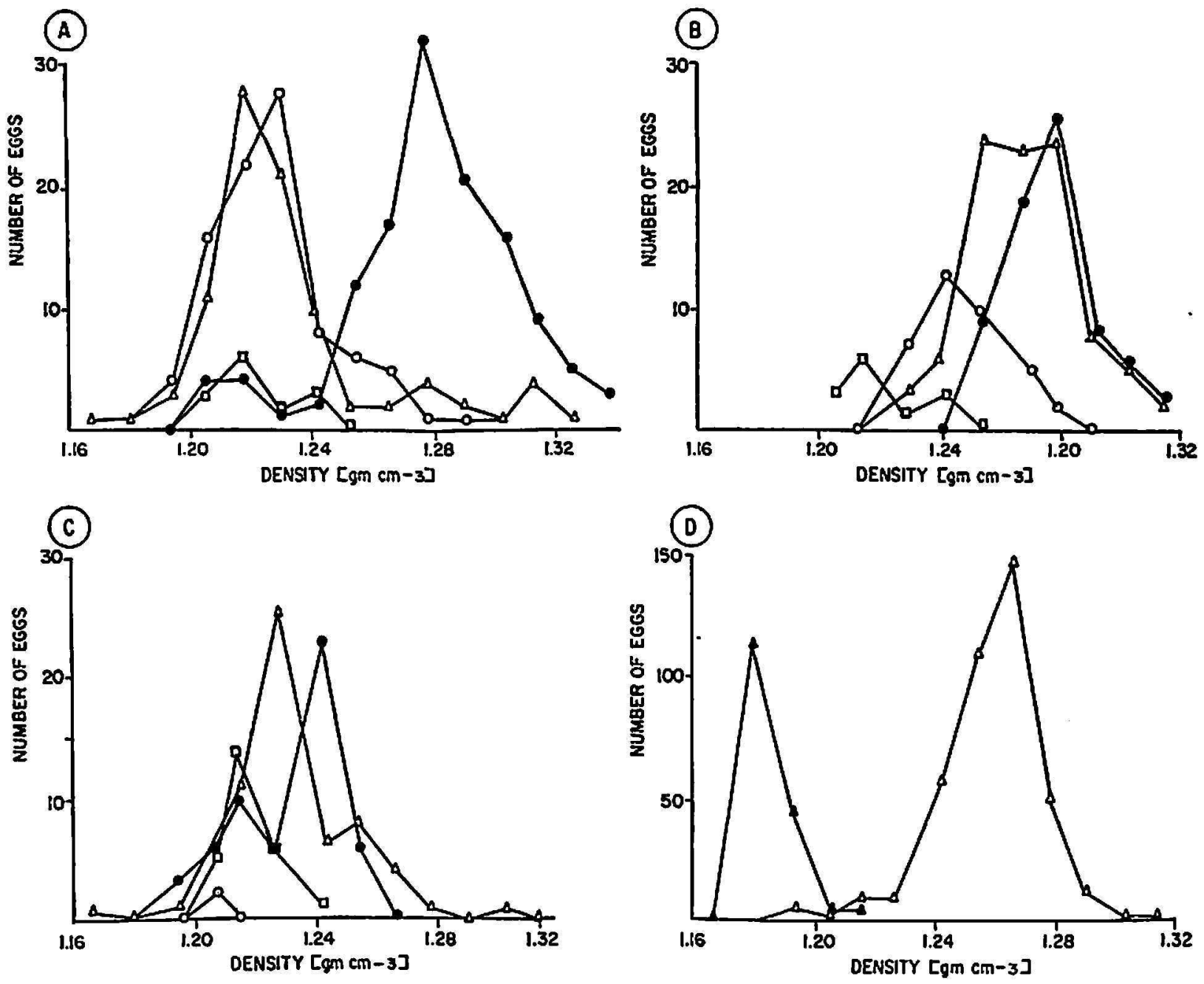

FIG. 1.-Density distribution of $S$. mansoni eggs after centrifugation: A, Freshly isolated eggs; B, 2-week old eggs; C, eggs treated with 10 percent formalin; and D, human faecal eggs. $(O=$ immature eggs; $\Delta=$ mature eggs; $O$ degenerated eggs; $\square=$ miracidia; and $\mathbf{\Delta}=$ Trichuris eggs.)

of the hydrated particles, has been used to determine the apparent density of Schistosoma mansoni and Fasciola hepatica eggs. Preliminary experiments with $S$. mansoni eggs demonstrated that the eggs had a density greater than 1.3 in sucrose solutions and 1.4 in $\mathrm{ZnCl}_{2}$ solutions. The data in figures 1 and

1 Manuscript submitted to Editorial Board November 1, 1971.

2 Work conducted at the Puerto Rico Nuclear Center, University of Puerto Rico, Rio Piedras, P.R., under Contract AT-(40-1)-1833 for the U.S. Atomic Energy Commission. 

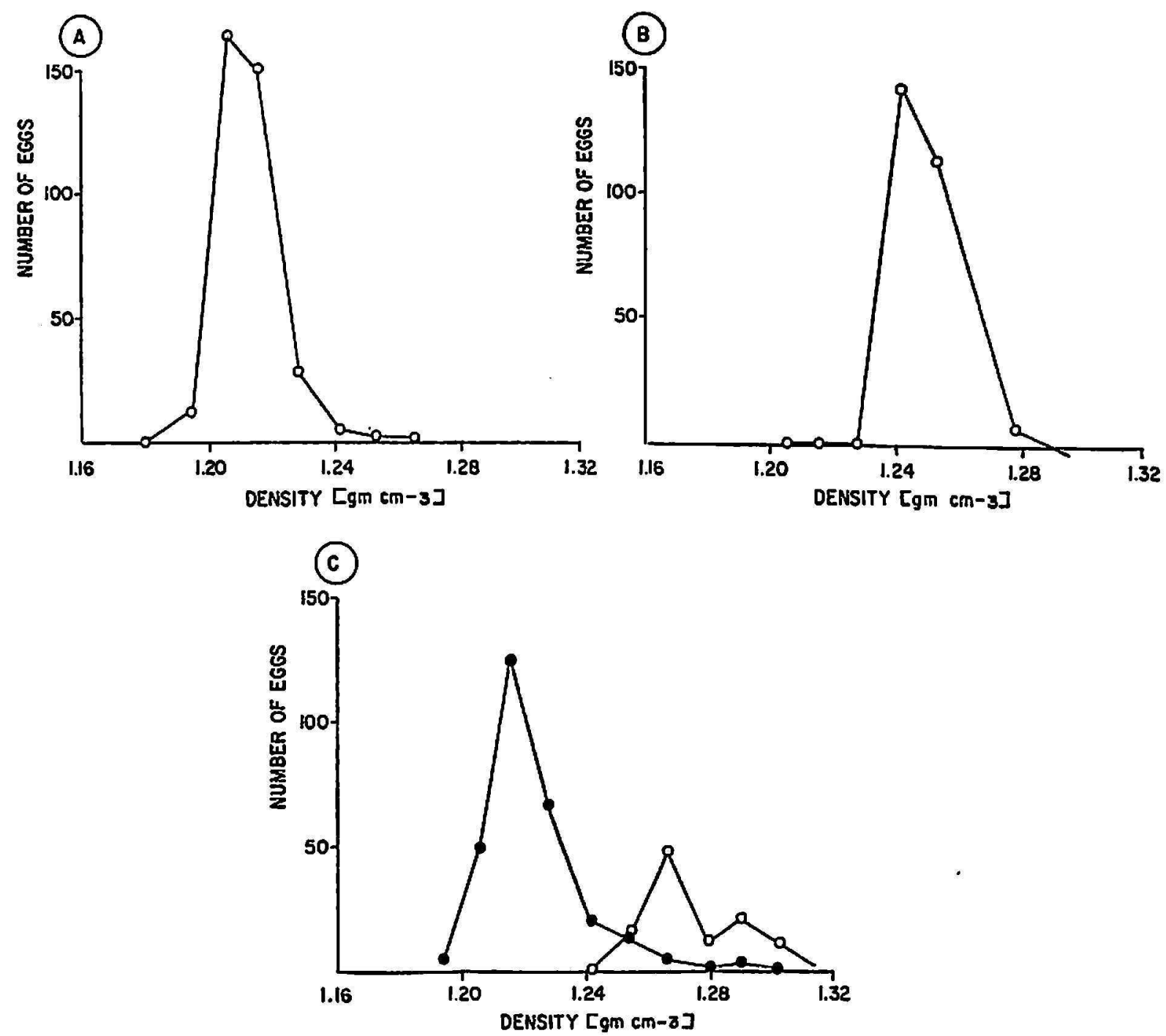

Fia. 2.-Density distribution of $F$. hepatica eggs after centrifugation: A, Undeveloped eggs; $\mathrm{B}$, eggs after 4 days development at $26^{\circ}-28^{\circ} \mathrm{C}$. and $\mathrm{C}$, eggs after 10 days development at $26^{\circ}-28^{\circ} \mathrm{C}$. $(\mathrm{O}=$ undamaged eggs; $\mathrm{O}=$ distorted eggs.)

2 were obtained using preformed linear $\mathrm{ZnSO}_{4}$ gradients with densities between 1.18 and 1.45 and centrifuging in a Beckman $^{3}$ SW39 swinging bucket rotor at 30,000 r.p.m. for 20 minutes.

The data in figure 1,A shows that there was some separation of the eggs in different stages of development after centrifugation of $S$. mansoni eggs freshly isolated from mouse liver. ${ }^{4}$ The distribution of the eggs shifted to higher densities after storage at $4^{\circ} \mathrm{C}$. for 2 weeks (fig. 1,B) and after treat-

3 Trade names are used in this publication solely for the purpose of providing specific information. Mention of a trade name does not constitue a guarantee or warranty of the equipment by the Agricultural Experiment Station of the University of Puerto Rico, Public Health Service or U.S. Department of Health, Education and Welfare, or an endorsement of other equipment not mentioned.

1 Ritchie, L. and Berríos-Durán, L. A., A simple procedure for recovering Schistosoma eggs in mass tiasue, J. Parasitol. 47: 363, 1961. 
ment with formalin (fig. 1,C). Eggs isolated from human faeces and allowed to stand for 2 weeks gave the distribution shown in figure 1,D. Since the Trichuris trichura eggs in the faecal specimen were at the top of the gradient, one can only say that their apparent density is 1.2 or less.

$F$. hepatica eggs isolated from the gall-bladder of infected cattle ${ }^{5}$ formed one sharp peak on the density gradient (fig. 2,A) with an apparent density of 1.21. The apparent density increased to 1.24 after 4 days of development (fig. 2,B). After 10 days development (fig. 2,C) most of the eggs were ready to hatch. The latter eggs were highly distorted, probably because of permeability to the concentrated $\mathrm{ZnSO}_{4}$ solution.
Delfín de León-Dancel
Agricultural Experiment Station
Raymond A. Brown
Puerto Rico Nuclear Center.
Wilda B. Knight
$U$.S. Department of Health, Education, and Welfare

- de León-Dancel, D., On the experimental infection of Pomacea australis (d' Orbiguy) refractive for Fasciola hepatica $(\mathrm{L}$.) and receptive to Angiostrongylus cantonensis (Chen.), J. Agr. Univ. P.R. 54 (2): 297-305, 1970. 